\title{
As dificuldades de compreender o sistema totalitário: a celeuma provocada por Origens do totalitarismo de Hannah Arendt
}

\author{
The difficulties of undestanting the totalirian system: \\ the uproar caused by Hannah Arendt's Origins of Totalitarianism
}

DOI: $10.20873 / \mathrm{rpv} 6 \mathrm{n} 2-02$

Maria Cristina Müller

Orcid: 0000-0001-5467-851X

Email: mcrismuller@hotmail.com

\begin{abstract}
Resumo
O objetivo do presente texto é apresentar algumas das críticas que Origens do Totalitarismo de Hannah Arendt recebeu e as discussões que suscitaram, demonstrando as dificuldades de compreender o sistema totalitário e a novidade que a interpretação de Arendt gerou. Entre os principais críticos estão Raymond Aron, Waldemar Gurian, Kurt Blumenfeld, Eric Voegelin e Karl Jaspers. Serão apresentadas algumas das críticas para, em seguida, estabelecer a discussão a partir da argumentação contida nos textos de Arendt. Serão utilizadas como principais referências as obras de Arendt Origens do Totalitarismo e A condição humana, os textos "Compreensão e política", "Sobre a natureza do totalitarismo: uma tentativa de compreensão", "A tradição e a época moderna", "O conceito de história: antigo e moderno", "Que é autoridade" e "Uma réplica a Eric Voegelin". Também serão utilizadas as cartas de Arendt com Karl Jaspers e Kurt Blumenfeld e alguns dos textos dos críticos. As biografias sobre Arendt de Elizabeth Young-Bruehl, Sylvie Courtine-Dénamy e Laure Adler e textos de Odílio Alves Aguiar e Daiane Eccel serão utilizadas como fontes importantes. Concluiu-se que Arendt desafiava a compreensão ao não simplesmente descrever os acontecimentos, mas ao realizar aquilo que acreditava ser a própria filosofia, um exercício de pensamento.
\end{abstract}

\section{Palavras-chave}

Hannah Arendt; Totalitarismo; Origens do Totalitarismo.

\begin{abstract}
The aim of this text is to present some of the criticisms that Hannah Arendt's Origins of Totalitarianism received and the discussions they aroused, demonstrating the difficulties in understanding the totalitarian system and the novelty that Arendt's interpretation generated. Among the main critics are Raymond Aron, Waldemar Gurian, Kurt Blumenfeld, Eric Voegelin and Karl Jaspers. Some of the criticisms will be presented to, then, establish the discussion based on the arguments contained in Arendt's texts. The main references will
\end{abstract}


be the works of Arendt Origins of Totalitarianism and The Human Condition, the texts "Understanding and politics", "On the nature of totalitarianism: an essay in understand", "Tradition and the modern age", "The concept of history: ancient and modern", "What is authority" and "A reply to Eric Voegelin". Arendt's letters with Karl Jaspers and Kurt Blumenfeld and some of the critics' texts will also be used. The biographies on Arendt by Elizabeth Young-Bruehl, Sylvie Courtine-Dénamy and Laure Adler and texts by Odílio Alves Aguiar and Daiane Eccel will be used as important sources. It was concluded that Arendt challenged understanding by not simply describing events, but by carrying out what she believed to be philosophy itself, an exercise in thought.

\section{Keywords}

Hannah Arendt; Totalitarianism; Origins of Totalitarianism.

No texto Compreensão e política (1993, p. 39-53), escrito em 1953, Arendt estabelece uma importante reflexão a partir das críticas dirigidas à obra Origens do Totalitarismo. Entre os principais críticos estão Raymond Aron, Waldemar Gurian, Kurt Blumenfeld, Eric Voegelin e Karl Jaspers. 0 objetivo do presente texto é apresentar algumas dessas críticas e as discussões que suscitaram, demonstrando as dificuldades de compreender o sistema totalitário e a novidade que a interpretação de Arendt gerou. Serão utilizadas, como principais referências, as obras de Arendt Origens do Totalitarismo e A condição humana, os textos Compreensão e política, Sobre a natureza do totalitarismo: uma tentativa de compreensão, A tradição e a época moderna, O conceito de história: antigo e moderno, Que é autoridade e Uma réplica a Eric Voegelin. Também serão utilizadas correspondências de Arendt com Karl Jaspers e Kurt Blumenfeld. Alguns dos textos dos críticos de Arendt servirão para a compreensão da crítica que fazem à Arendt; no entanto, não é interesse, neste momento, reconstruir as teorias desses críticos. As biografias sobre Arendt de Elizabeth Young-Bruehl, Sylvie Courtine-Dénamy e Laure Adler serão utilizadas como fontes importantes para compreender os contextos. E, por fim, os comentários de Odilio Alves Aguiar e Daiane Eccel comporão referências importante para a discussão.

Inicialmente, é importante lembrar que Compreensão e política elabora uma reflexão acerca da compreensão e da reconciliação ${ }^{1}$. Diante das primeiras notícias dos massacres

\footnotetext{
${ }^{1}$ A discussão acerca da compreensão foi desenvolvida no texto MÜLLER, M. C. 0 imperativo da compreensão In: OLIVEIRA, K. L DE E SCHAPER, V. G. (Org.). Hannah Arendt: uma amizade em comum. São Leopoldo: Oikos/EST, 2011, p. 11-23.
} 
administrativos de pessoas nos campos de extermínio, segundo Arendt (1993, p. 39), era imprescindível que todos mergulhassem na tarefa de compreender o que efetivamente havia acontecido com a civilização da qual todos faziam parte, com o mundo que lhes servia de lar e com os padrões que até então serviam para o estabelecimento do certo e do errado, do bem e do mal. 0 pressuposto do qual Arendt partiu era o de que todo ser humano, enquanto um indivíduo que vive neste mundo e dele faz parte desde o nascimento até a morte, deve aprender a lidar com a realidade que inevitavelmente o cerca e reconciliar-se com ela. Assim, o imperativo da compreensão aponta para a necessidade da reconciliação com este mesmo mundo, que produz, muitas vezes, fenômenos brutais e horrendos. Arendt partia da constatação de que os padrões morais à época, sejam os mandamentos religiosos ou as regras socialmente estabelecidas, não foram suficientes para impedir as atrocidades cometidas contra a dignidade da pessoa humana. 0 mandamento "Não Matarás" se transformou, da noite para o dia, em "Matarás" e raros foram os exemplos de resistência e de questionamento a essa transformação. Nenhuma explicação conhecida era suficiente para oferecer respostas plausíveis àquilo que havia acontecido e o porquê dos acontecimentos. Desse modo, a única conclusão aceitável seria a de que a realidade do século XX apontava para um fenômeno de ruptura com a tradição do pensamento político e moral. Para Arendt, uma verdade única e absoluta a explicar tudo e a existência de uma única explicação para a totalidade dos fenômenos humanos eram inviáveis; neste sentido, a compressão se mostrava como tarefa de uma vida e um empreendimento sempre inacabado. Constantemente, os seres humanos precisam compreender e se reconciliar com a realidade, que é diversa das certezas de ontem e das expectativas do que será amanhã, buscando significado e sentido para que assim possa seguir a agir no mundo. Dito isso, é possível retornar à proposta anunciada para este texto.

Em nenhum momento do texto Compreensão e política Arendt nomeia os críticos, apresenta contestações diretas ou objeta alguma discordância nominal dirigida explicitamente a alguns deles. Mesmo que Arendt adote, em muitos momentos, um tom irônico, em geral é bastante sutil. Percebe-se que as críticas que Arendt recebeu possibilitaram nova reflexão, mesmo que isso não tenha alterado suas convicções, o uso de algum dos conceitos ou a interpretação que fazia deles. 0 que aparece claramente no texto Compreensão e política é a discussão teórica 
de Arendt com seus opositores ao estabelecer novas distinções e aprofundar conceitos com maior detalhamento. A partir disso é possível dizer que Arendt estava disposta à discussão e nutria uma disposição para o debate.

Raymond Aron, no artigo A essência do totalitarismo segundo Hannah Arendt, publicado na edição de janeiro de 1954 da revista Critique e, posteriormente, incluído no livro Maquiavel e as tiranias modernas, considera a obra Origens do totalitarismo importante pela análise que apresenta do totalitarismo, mas, ao mesmo tempo, avalia que Arendt exagera os defeitos e as qualidades dos seres humanos e dos regimes políticos que descreve. Aron discorda do pressuposto de que a ideologia racista poderia justificar a morte de quase seis milhões de pessoas.

Para Arendt, a ideologia tem papel crucial para se entender como foi possível as "sociedades respeitáveis", em geral, se manterem coniventes e silenciosas diante de governos capazes de ações brutais e indizíveis como as cometidas pelos regimes totalitários, principalmente o nazismo; contudo, a partir disso, não se pode dizer que a ideologia racista é a única e definitiva resposta aos crimes e ao tipo de mal que atingiu o mundo no século XX. Deve-se lembrar que, para Arendt, o sucesso do totalitarismo e o extermínio de quase seis milhões de pessoas, no caso da Alemanha, se sucedeu em uma sociedade atomizada, composta por homens e mulheres isolados, desarraigados e supérfluos. A qualquer momento podia-se escolher outro grupo de vítimas que serviriam para alimentar o sistema de dominação total. 0 importante era a ideologia como forma de dominação independentemente do conteúdo que propagasse - raça, classe. A dominação total reunia ideologia, burocracia e terror, de modo que Arendt define o totalitarismo como uma nova forma de governo que domina interna e externamente os indivíduos. Essa nova forma de governo tinha como princípio a ideologia e sua natureza era calcada no terror - medo - e na burocracia - governo de ninguém. Desde modo, não se pode dizer que a grande conclusão de Arendt acerca da análise do totalitarismo se limita à ideologia racista. Tal compreensão do livro Origens do totalitarismo é um exemplo claro do ponto de divergência de Arendt com os teóricos de sua época.

Sylvie Courtine-Dénamy (1994, p. 233) argumenta que, apesar de Raymond Aron descrever como irônica e trágica a maneira com que Arendt contava os fatos, o que, segundo ele, faz desaparecer a história real, muitos aspectos das análises de ambos convergem e o debate 
entre eles se estenderá por muito tempo. No livro Democracia e Totalitarismo, escrito muitos anos depois (1965), Aron defende a ideia de que há uma continuidade da tirania no totalitarismo, e que não há uma única matriz para os totalitarismos. Essas conclusões, contudo, mantêm contrariedade com o exposto por Arendt na obra Origens do Totalitarismo. Para Arendt, houve uma grande ruptura com o que era compreendido como civilização e com suas verdades. Os padrões teóricos existentes não eram suficientes para dar-lhe sentido, ele era desconhecido e inexplicável segundo as teorias acerca das formas de governo e do estabelecimento de juízos morais. Com isto, observa-se a importância central do aspecto de ruptura na análise de Arendt acerca do totalitarismo e dos eventos ligados a esse regime, principalmente para a construção dos conceitos de compreensão e de reconciliação.

Para Arendt, não é possível explicar o totalitarismo a partir de uma ideia de continuidade histórica, vista como uma sucessão temporal de acontecimentos que não se rompem, mas continuam incessantemente. Arendt diverge do conceito moderno de história que pensa a história como processo, isso é, como sucessão temporal, que usa o princípio da causalidade, típico das ciências naturais, como seu pressuposto. Pode-se dizer que Arendt não concorda com esse conceito, principalmente, porque ele não comporta a dimensão da liberdade humana. Se todos os eventos decorrem de um processo contínuo, os seres humanos não poderiam interferir, portanto, os acontecimentos, como sucessão temporal, como processo, independeriam das ações individuais dos seres humanos. Toda história seria uma inevitável causalidade de modo que a ação livre seria impossível; o que poderia levar ao absurdo da inexistência de atribuição de culpa e responsabilidade individual sobre os acontecimentos. Arendt, nos textos A tradição e a época moderna, $O$ conceito de história: antigo e moderno e $O$ que é autoridade? - posteriores a Origens do totalitarismo - esclareceu o seu pressuposto acerca do fenômeno da ruptura da tradição e apresentou seu entendimento de história, isso é, estabeleceu o lugar de onde partia e o porquê de suas conclusões.

Eric Voegelin, segundo apresentado por Laure Adler (2007, p. 330), admira a ambição teórica, o brilhantismo e as intuições profundas de Arendt acerca do totalitarismo; contudo, critica-a dizendo que lhe falta domínio filosófico quando estende suas intuições até as últimas consequências, algo que, por outro lado, ele entende como perfeitamente compreensível 
naqueles tempos confusos. Voegelin também interroga o uso recorrente de metáforas a que Arendt se apegava. Contudo, o que mais o perturbava, e também a Waldemar Gurian, era a conclusão de Arendt de que o totalitarismo "modificara a natureza humana". Para Voegelin, era impensável mudar a natureza de alguma coisa, pois no instante que se modifica a natureza de algo, essa "coisa" deixa de ser o que era, isso é, a "coisa" deixa de existir. ${ }^{2}$

Para Elizabeth Young-Bruehl (1997, p. 235-6), o que Arendt fazia quando se referia à "natureza humana" era pensar a destruição que o totalitarismo empreendia contra as condições existenciais da vida humana. 0 totalitarismo, quando atingia o domínio total dos homens e mulheres, os incapacitava de pensarem por si mesmos e de agirem livremente no espaço próprio para a ação - a esfera pública do mundo, o mundo comum. 0 que inquietava Arendt era a inexistência, sob os regimes totalitários, do espaço em que as pessoas podem aparecer e se mostrar aos demais - espaço da pluralidade que garante a singularidade de cada um - e, mais assustadoramente, os fenômenos derivados do acontecimento totalitário, no sentido do apagamento do bom senso. Arendt jamais postulou a existência de alguma essência oculta e invisível que teria por resultado o totalitarismo. Ela queria respostas às questões: 0 que é que se passou? Porque é que se passou? Como foi possível? Sua discussão sobre a natureza humana pode ser constatada no livro A condição humana, especialmente quando ela expõe que uma natureza humana somente poderia ser conhecida por Deus e que, se o ser humano a pretendesse conhecer, era como se quisesse saltar por sobre sua própria sombra. Segundo Arendt (2010, p. 11 a 13), o ser humano somente pode responder à pergunta "Quem sou? Cuja resposta é - Um homem. Ele jamais poderá responder a pergunta “O que sou?" - essa pergunta somente poderá ser respondida por Deus, isso é, aquela divindade que criou o homem e a mulher. Para ela, a pergunta acerca da natureza humana envolve a teologia, o que significa que necessita de uma resposta divinamente revelada.

Segundo a interpretação de Young-Bruehl (1997, p. 236), as objeções feitas por Voegelin distraíam a atenção do que era fundamental: a responsabilidade de cada um para com a

\footnotetext{
${ }^{2}$ A crítica de Eric Voegelin ao livro Origens do totalitarismo bem como a resposta de Arendt estão publicadas na Review of Politics de janeiro de 1953, pp. 68-76. A resposta de Arendt consta traduzida no livro Compreender: formação, exílio e totalitarismo (ensaios), coletânea de textos de Arendt de 1930 a 1954.
} 
realidade do mundo que partilha. Arendt teria estabelecido que o objetivo do totalitarismo seria a manipulação da natureza humana dentro de sua tentativa de olhar para os fatos desprovida dos preconceitos tradicionais, no sentido de se colocar distante dos padrões tradicionais de análise. Talvez, por isso, as críticas. Afinal, ela não utilizava teorias que usualmente ou até então eram comuns para explicar os fenômenos históricos. Diante das catástrofes do século XX, Arendt percebeu que esses padrões de explicação não eram suficientes.

Kurt Blumenfeld elogia como brilhante a análise política que Arendt expôs em Ideologia e terror: uma nova forma de governo (YOUNG-BRUEHL, 1997, p. 235). No ensaio, Arendt trata da eliminação do espaço entre-os-homens, o domínio total e a manipulação da natureza humana. 0 ensaio Ideologia e terror foi construído e incorporado à obra Origens do Totalitarismo posteriormente; somente na segunda edição, a de 1958, o texto aparece como o penúltimo capítulo da segunda edição aumentada de Origens do Totalitarismo, publicada em $1958^{3}$ (YOUNGBRUEHL, 1997, p. 255 e nota 28 p. 471). Sylvie Courtine-Dénamy (1994, p. 232) menciona que uma versão preliminar do ensaio foi preparada inicialmente como um resumo de Origens do Totalitarismo para uma conferência que Arendt proferiu na Universidade Notre-Dame (Indiana/EUA) em novembro de 1950, conduzida por Waldemar Gurian - redator-chefe da Review of Politics -, antes da publicação do livro em 1951, e também para uma conferência pronunciada em Heidelberg em 1952. Além disso, Courtine-Dénamy anuncia que Ideologia e terror seria o prefácio de uma nova pesquisa de Arendt sobre marxismo. Tal pesquisa foi financiada pela Fundação Guggenheim. Arendt recebeu uma bolsa anual de dois anos; tratava-se de uma distinção honorífica importante tanto financeiramente como pelo reconhecimento de sua contribuição teórica e foi a primeira bolsa - 1952 - que Arendt recebeu de uma fundação de pesquisa. Esta nova pesquisa previa um livro que seria intitulado Elementos totalitários do marxismo ${ }^{4}$ e daria continuidade a Origens do Totalitarismo. Contudo, a pesquisa para o livro transformou-se em algo distinto do previsto: o primeiro capítulo, que discutiria as dificuldades de compreensão

\footnotetext{
${ }^{3} \mathrm{Na}$ edição brasileira aparece sob o título Ideologia e terror: uma nova forma de governo, como epílogo do livro Capítulo 4 da Parte III - Totalitarismo.

${ }^{4}$ Arendt nunca escreveu esse livro como havia previsto no projeto. Os fragmentos estão publicados no livro $O$ que é política, organizado a partir dos manuscritos por Ursula Ludz, traduzido para o português por Reinaldo Guarany e publicado pela Bertrand Brasil em 1999.
} 
que o sistema totalitário trouxe, transformou-se no texto Compreensão e política, publicado na Partisan Review em 1953; o segundo capítulo, que examinaria a grande tradição e apresentaria o ponto exato em que esta se rompeu, tornou-se o texto A Tradição e a Época Moderna, publicado na Partisan Review em 1954; o terceiro capítulo, que deveria tratar da lei e do poder como os dois pilares que sustentam todas as formas tradicionais de governo, foi completamente modificado e transformou-se no texto O que é Autoridade?5, publicado em 1958 na American Society of Political and Legal Philosophy, Nomos I: Authority; Nova York, Bobbs-Merrill, volume coordenado por Carl J. Friedrich; o quarto capítulo trataria de Montesquieu e proporcionaria os instrumentos para distinguir o totalitarismo de todas as outras formas de governo do passado, inclusive os tirânicos. Os elementos previstos para este quarto capítulo são os elementos que aparecem no ensaio Ideologia e terror: uma nova forma de governo. É curioso perceber que um único texto teria servido para vários propósitos. 0 ensaio foi publicado em julho de 1953 na Review of Politics; uma versão diminuída, em alemão, teria sido a contribuição de Arendt a um livro que estava sendo escrito em homenagem a Karl Jaspers - Festschrift -, por ocasião do aniversário de 70 anos do filósofo.

Tudo leva a crer que Arendt tenha incorporado o ensaio Ideologia e terror ao livro Origens do Totalitarismo como resultado das suas reflexões a partir das críticas que a primeira versão do seu livro suscitou; é possível especular que a pesquisa sobre o totalitarismo continuava a fomentar a reflexão de Arendt e as discussões com os críticos demandavam ainda mais a esta reflexão. Isso, porém, não significa que Arendt tenha "desistido da convicção de que aquilo que não tem precedente não pode ser inferido pelo precedente, bem como sua advertência de que as teorias de progresso e de ruína encobrem a visão dos acontecimentos sem precedentes" (YOUNG-BRUEHL, 1997, p. 254). Apesar da celeuma, pode-se sustentar que Arendt manteve a convicção de que todo o horror causado pelo nazismo não poderia ser explicado pelas

\footnotetext{
${ }^{5}$ Deve-se também mencionar que os textos $A$ tradição e a época moderna e $O$ que é autoridade? foram publicados em 1961 no livro Entre o passado e o futuro, organizado por Arendt como tentativa de reexaminar criticamente os principais conceitos do pensamento político tradicional e moderno, tais como: autoridade, governo, poder, lei, guerra etc. Esse projeto deveria resultar num livro de introdução à política, mas resultou no livro Entre o passado e o futuro.
} 
categorias da tradição e de que o totalitarismo não estaria potencialmente contido num evento do passado. Ela precisava esclarecer seus pressupostos, dizer de onde e por que falava.

De acordo com Laure Adler (2007, p. 330 e 356), Karl Jaspers manifestou-se inicialmente apenas sobre o texto de conclusão do livro - À guisa de conclusão ${ }^{6}$ - que Arendt lhe confiou pouco antes de ser enviado para a impressão em início de 1951. Nessa época, Jaspers conhecia a totalidade do livro Origens do Totalitarismo apenas pela apresentação da obra que Arendt lhe fez pessoalmente quando o visitou na Basiléia. Em uma carta de 15 de fevereiro de 1951 (ARENDT; JASPERS, 1992, p. 165-168), Jaspers elogia a veracidade com que Arendt narrou o fenômeno dos campos de internamento, mas apresenta duas questões de difícil resolução: a) como fazer para que cada um o reconheça? b) Yahvé não teria desaparecido demais? Jaspers também se manifestou, posteriormente, sobre o texto Ideologia e terror. Ele o considerou profundo e mais compreensível do que as novecentas páginas de Origens do totalitarismo - que nessa época já havia lido - mas criticou como exagerada a pretensão de Arendt de negar a continuidade na história para melhor receber o novo. Segundo Adler (2007, p. 330), Jaspers não compreendia o que era esse "novo". No último parágrafo de Ideologia e Terror, Arendt apresenta esse conceito de "novo", mas não o aprofunda. Isto ela fez, inicialmente, no texto Compreensão e Política e o aprofundou em A condição humana, quando se dedicou a uma importante reflexão sobre a natalidade enquanto começo e início, como aquilo que move cada ser humano na ação.

Todos os críticos concordavam acerca de um aspecto: Arendt exagerara. Ela, por sua vez, apreciava as críticas que recebia e a polêmica que seu livro suscitava, mesmo entre seus amigos, pois isso significaria, no mínimo, que o que escrevera e concluíra tinha sentido e desestabilizara; Arendt queria discutir. Talvez a única crítica que tenha provocado um mal-estar maior foi a que recebeu de Kurt Blumenfeld acerca da análise da questão judaica. Blumenfeld adverte que uma análise mal-intencionada do livro de Arendt poderia concluir que havia um "ódio de si" por parte do povo judeu (ADLER 2007, p. 338-9). Sobre a censura comum de exagero, Arendt

\footnotetext{
${ }^{6}$ Essa conclusão é posteriormente retirada do livro Origens do Totalitarismo, não há tradução dessa primeira edição para a língua portuguesa.
} 
não se reporta a nenhum dos críticos e responde apenas a Jaspers, em carta de 25 de janeiro de 1952:

A realidade exagerou tanto em nosso século que podemos dizer sem medo que a realidade é 'exagerada'. Nosso pensamento, que gosta acima de tudo das vias habituais, mal consegue sobreviver. Os 'exageros' de meu pensamento - que se esforça sempre em exprimir algo de adequado num tom, se possível, adequado - parecerão de fato inacreditavelmente radicais se os medirmos não pela realidade, mas por aquilo que dizem sobre o mesmo assunto outros historiadores que supunham que tudo era exatamente assim (ARENDT; JASPERS, 1992, p 175-176, tradução nossa).

Segundo Odílio Alves Aguiar (2001, p. 217-18), os críticos não conseguiam entender que, em nenhum momento, Arendt pretendeu escrever um livro de ciência histórica, isso é, um livro em que os fatos fossem reproduzidos como descrições do ocorrido, como reconstituição dos acontecimentos tal e qual ocorreram. Arendt pretendia realizar um exercício de pensamento, objetivando instigar à compreensão. Isto significa dizer que o livro era para ser lido como livro de filosofia, não de ciência ou de história. Arendt pretendia encontrar um sentido que pudesse iluminar os trágicos acontecimentos do século XX, e, ao compreender os movimentos totalitários, pudesse haver algum sentido para cada um no mundo e para o próprio mundo. 0 método que Arendt utilizou para conduzir esse importante exercício do pensamento foi a narrativa e um dos recursos foi o de apresentar os conceitos através de metáforas. Nas palavras da autora: "Eu não escrevi uma história do totalitarismo, mas uma análise em termos históricos dos elementos que se cristalizaram no totalitarismo" (ARENDT, 1993, p. 403). Arendt desafiava a compreensão ao não simplesmente descrever os acontecimentos, mas ao realizar aquilo que acreditava ser a própria filosofia, um exercício de pensamento.

\section{Referências}

ADLER, L. Nos passos de Hannah Arendt. Trad. T. Levy; M. Jacques. Rio de Janeiro/São Paulo: Record, 2007. AGUIAR, O. Filosofia e política no pensamento de Hannah Arendt. Fortaleza: UFC Edições, 2001.

ARENDT, H. A condição humana. 11. ed. Trad. R. Raposo. Revisão e Apresentação de Adriano Correia. Rio de Janeiro: Forense Universitária, 2010.

ARENDT, H. Compreender: Formação, exílio e totalitarismo (ensaios). 1930-1954. Trad. D. Bottman; Organização e introdução de Jerome Kohn. São Paulo: Companhia das Letras; Belo Horizonte: Editora UFMG, 2008. 
ARENDT, H. Responsabilidade e julgamento. Trad. R. Eichenberg. Edição americana Jerome Kohn; Revisão técnica Bethânia Assy e André Duarte. São Paulo: Companhia das Letras, 2004.

ARENDT, H. 0 que é política? 3. ed. Trad. R. Guarany. Rio de Janeiro: Bertrand Brasil, 2002.

ARENDT, H. Origens do totalitarismo: Anti-semitismo, Imperialismo, Totalitarismo. Trad R. Raposo. 2ª . reimpressão. São Paulo: Companhia das Letras, 1997.

ARENDT, H. Compreensão e política. In: ARENDT, H. A dignidade da política: Ensaios e conferências. Trad. H. Martins. Rio de Janeiro: Relume-Dumará, 1993.

ARENDT, H. A reply to Eric Voegelin. In: Essays in understanding. New York: HB\&C, 1993a.

ARENDT, H. Entre o passado e o futuro. Trad. M. W. Barbosa de Almeida. 3. ed. São Paulo: Editora Perspectiva, 1992.

ARENDT, H.; BLUMENFELD, K. Correspondance: 1933-1963. Paris: Desclée de Brouwer, 2012.

ARENDT, H.; JASPERS, K. Correspondence: 1926-1969. New York: A Harvest Book/Harcourt Brace \& Company, 1992.

ARON, R. A essência do totalitarismo segundo Hannah Arendt. In: Critique, jan. 1954.

ARON, R. Democracia e totalitarismo. Trad. F. Montenegro. Lisboa: Presença, 1966.

ARON, R. Machiavel et les tyrannies modernes. Paris: De Fallois, 1993.

BIRULÉS, F. La pasión por comprender. Revista Archipiélago: Cuadernos de Critica de la Cultura. n. 30, 1997.

COURTINE-DÉNAMY, S. Hannah Arendt. Trad. L. Figueiredo. Lisboa: Instituto Piaget, 1994.

ECCEL, D. Debate sobre o totalitarismo: a troca de correspondências entre Hannah Arendt e Eric Voegelin. Lua Nova, São Paulo, 101: p. 141-174, 2017.

GURIAN, W. Totalitarismo como religião política. In: FRIEDRICH, Carl J. (Org.). Totalitarism. Nova Iorque: Grosset \& Dunlap, 1964.

KOHLER, L.; SANER, H. Hannah Arendt, Karl Jaspers (Orgs.). Correspondance (1926-1969). Trad. R. Kimber; R. Kimber. San Diego/Nova York/Londres: Harcourt Brace, 1992.

MÜLLER, M. C. Totalitarismo e poder político em Arendt. In: CHITOLINA, C. L. et.al. (Orgs.). Estado, indivíduo e sociedade: Problemas contemporâneos. Judíaí: Paco Editorial, 2012. pp. 307 - 325.

MÜLLER, M. C. $O$ imperativo da compreensão. In: OLIVEIRA, K. L. de; SCHAPER, V. G. (Org.). Hannah Arendt: Uma amizade em comum. São Leopoldo: Oikos/EST, 2011, p. 11-23.

VOEGELIN, E. "The Origins of Totalitarianism". The Review of Politics, vol. 15, no. 1, [University of Notre Dame du Lac on behalf of Review of Politics, Cambridge University Press], 1953, pp. 68-76, http://www.jstor.org/stable/1404747.

YOUNG-BRUEHL, E. Por amor ao mundo: A vida e a obra de Hannah Arendt. Trad. A. Trânsito. Rio de Janeiro: Relume-Dumará, 1997. 


\section{Maria Cristina Müller}

Pós-Doutora em Filosofia pela Universidade Federal de Goiás - UFG/GO. Doutora em Filosofia pela Universidade Federal de São Carlos - UFSCar/SP. Mestre em Filosofia pela Pontifícia Universidade Católica do Rio Grande do Sul - PUCPOA. Graduada em Filosofia Licenciatura Plena pela Universidade de Passo Fundo UPF/RS. Professora Associada da Universidade Estadual de Londrina - UEL/PR - onde atua no Departamento de Filosofia desde o ano de 2000. Docente do Programa de Pós-Graduação em Filosofia da Universidade Estadual de Londrina. Foi Coordenadora do GT Filosofia Política Contemporânea da ANPOF. Concentra suas pesquisas na área de Filosofia Política e Ética com ênfase em Hannah Arendt. Desde 2018 também investiga o tema A Presença da Mulher na Filosofia. 